\title{
Erratum to: Changes in Bone Mineral Density in Women Following 1-Year Gastric Bypass Surgery
}

\author{
Daniela Schaan Casagrande ${ }^{1,2,3} \cdot$ Giuseppe Repetto $^{4}$ - Claudio Corá Mottin ${ }^{2,4}$. \\ Jatin Shah $^{3} \cdot$ Ricardo Pietrobon $^{3} \cdot$ Mathias Worni $^{3} \cdot$ Beatriz D. Schaan ${ }^{1,5}$
}

Published online: 15 July 2015

(C) Springer Science+Business Media New York 2015

Erratum to: OBES SURG (2012) 22:1287-1292

DOI 10.1007/s11695-012-0687-z

The units for serum 25-OH-vitamin D in the "abstract" section on page 1287 and in Table 3 (Characterization of the subjects studied according to their bone metabolism) on page 1290 should be $\mathrm{ng} / \mathrm{mL}$ instead of $\mathrm{pg} / \mathrm{dL}$.

The online version of the original article can be found at http://dx.doi.org/ 10.1007/s11695-012-0687-z.

\footnotetext{
Beatriz D. Schaan

beatrizschaan@gmail.com
}

1 Postgraduate Program in Medical Sciences: Endocrinology and Metabolism, Hospital de Clinicas de Porto Alegre, Universidade Federal do Rio Grande do Sul, Porto Alegre, Brazil

2 Obesity and Metabolic Syndrome Center of Hospital São Lucas, Pontificia Universidade Católica do Rio Grande do Sul (COMHSL-PUCRS), Porto Alegre, Brazil

3 Research on Research Group, Department of Surgery, Duke University Medical Center, Durham, NC, USA

4 Faculty of Medicine, Hospital Sao Lucas, Pontificia Universidade Catolica do Rio Grande do Sul, Porto Alegre, Brazil

5 Endocrine Division, Hospital de Clínicas de Porto Alegre, Rua Ramiro Barcelos 2350, prédio 12, No. 4 andar, 90035-003 Porto Alegre, RS, Brazil 